\title{
A propósito de la oposición formal/material: cuatro aproximaciones interdisciplinares sobre un mismo tema On the formal/substantive opposition: four interdisciplinary approaches on the
} same subject

\author{
Oliver Roales Buján \\ Universidad de Málaga \\ ORCID ID 0000-0002-2039-185X \\ roales@uma.es
}
Cita recomendada:
ROALES BUJÁN, O. (2020). A propósito de la oposición formal/material: cuatro aproximaciones interdisciplinares sobre un mismo tema. Eunomía. Revista en Cultura de la Legalidad, 18, pp. 83-103.
doi: https://doi.org/10.20318/eunomia.2020.5265
Recibido / received: 23/03/2019
Aceptado / accepted: 29/01/2020

\begin{abstract}
Resumen
El pensamiento cientifista moderno que pretende obtener certezas mediante la búsqueda de afirmaciones indiscutibles sobre hechos irrefutables derivados de la protocolización y estandarización de procedimientos que nos alejen del debate sobre los valores e intereses particulares, ha olvidado que la formalización que requiere el diseño de todo procedimiento aplicable a casos concretos supone siempre la incorporación de finalidades relativas a valores e intereses. Este olvido, propio del pensamiento moderno, se ha visto acompañado de otra actitud: la hiperespecialización de las disciplinas, de manera que sus consecuencias y los debates sobre las mismas en una especie de constante reinvención de la rueda se han reproducido estérilmente. Mediante un estudio interdisciplinar que pone de manifiesto las líneas comunes en debates paradigmáticos en los campos del derecho, la retórica, la lingüística, la ciencia cognitiva y la inteligencia artificial simbólica, así como la teoría política, pretendemos poner de manifiesto la incapacidad de las teorías procesualistas de satisfacer esa aspiración de certeza y neutralidad absoluta propia de las sociedades postmetafísicas en sentido habermasiano.
\end{abstract}

\section{Palabras clave}

Debido proceso, debido proceso sustantivo, inteligencia artificial simbólica, filosofía política, J. Rawls, J. Habermas, C. Mouffe. 


\begin{abstract}
The modern scientificist thought that seeks to obtain certainty through the search for indisputable statements about irrefutable facts derived from the protocolization and standardization of procedures that take us away from the debate on particular values and interests, has forgotten that the formalization required for the design of any procedure applicable to specific cases always involves the addition of purposes related to values and interests. This oversight, typical of modern thought, has been accompanied by another attitude: the hyperspecialization of the disciplines, so that its consequences and the debates about them in a kind of constant reinvention of the wheel have been reproduced sterilely. Through an interdisciplinary study that highlights the common lines in paradigmatic debates in the fields of law, rhetoric, linguistics, cognitive science and symbolic artificial intelligence, as well as political theory, we intend to emphasize the inability of processual theories to satisfy an aspiration of absolute neutrality typical of postmetaphysical societies in the Habermasian sense.
\end{abstract}

\title{
Keywords
}

Due process, substantive due process, symbolic artificial intelligence, political philosophy, J. Rawls, J. Habermas, C. Mouffe.

SUMARIO. 1. Introducción. 2. Aproximación desde el derecho: el debido proceso sustantivo y su supuesto carácter contradictorio. 2.1. Consideraciones previas. 2.2. El debate doctrinal acerca de la supuesta imposibilidad lógica de lo procedimental-sustantivo. 3. Aproximación desde la filosofía: adjetividad sustantiva. 4. Aproximación desde la Ciencia Cognitiva y la inteligencia artificial simbólica: la inteligencia como un entramado de sistemas de reglas. 5. Aproximación desde la Teoría política. 6. Conclusión. Bibliografía.

\section{Introducción}

Ya lo entendamos como un fenómeno que sólo transcurre en nuestro fuero interno, o lo concibamos como un proceso de descubrimiento colectivo que conlleva la comunicación entre varios individuos -dialógica- o entre individuos y audiencias en diferentes contextos -retórica y política-, lo cierto es que el pensamiento, en cualquiera de sus posibles desenvolvimientos pragmáticos, parece exigirnos establecer en todo caso la más nítida distinción entre hechos y opiniones, entre el ser y el deber ser. Necesitamos conocer los hechos: sólo así, a pasitos cortos pero firmes, podremos trazar una descripción cierta de la realidad en todos sus ámbitos. Una descripción que nos permita, de una vez por todas, desterrar la incomunicación como fuente o como coartada de conflictos -como incomunicación real o fingida-. Sin embargo, mal que nos pese, hechos y opiniones no se dan nunca químicamente puros $^{1}$, y esa búsqueda de la certeza ha ido acompañada de una excesiva simplificación del problema, estableciéndose una separación artificiosa entre teoría y práctica que deviene a través de múltiples variantes en la hipóstasis del pensamiento racional, lo que conlleva una falaz reificación de lo abstracto y una confusión, en última instancia, de pensamiento y realidad. Un interesante ejemplo de esa reificación -signo de nuestros tiempos- es el olvido generalizado, más o menos consciente, del carácter puramente abstracto del par conceptual formal/material.

\footnotetext{
${ }^{1}$ STC 6/1988, de 21 de enero, FJ 5.
} 
Mediante este trabajo nos proponemos exponer esta cuestión por cuatro veces, tal y como se ha planteado desde cuatro disciplinas diferentes, cada una de ellas de manera independiente a las otras, aunque llegando a los mismos resultados. Esta aproximación interdisciplinar no solo nos permitirá entender mejor el problema que les es común, sino que servirá para ilustrar un caso paradigmático de falta de comunicación entre disciplinas propio de la hiperespecialización de la era moderna.

2. Aproximación desde el derecho: el debido proceso sustantivo y su supuesto carácter contradictorio

\subsection{Consideraciones previas}

Con antecedentes que se remontan al otorgamiento de la Carta Magna Inglesa en 1215 , en conjunción al desarrollo de una serie de mecanismos de protección que el common law o derecho común anglosajón estableció para los encausados criminalmente, la Constitución estadounidense incorporó a través de la aprobación de su Carta de Derechos en 1791, la llamada garantía constitucional del debido proceso. Recogida en su Quinta Enmienda, esta cláusula dispone que «a nadie [...] se le privará de su vida, su libertad o su propiedad sin el debido proceso legal». Históricamente, el significado de esta expresión habría conformado una garantía no meramente procedimental sino sustantiva, derivando una obligatoria sujeción al derecho común en los casos criminales de mayor gravedad, circunstancia que refleja Sir Edward Coke (1642, p. 50) al señalar que las expresiones «due process of law» y "law of the land» tenían una consideración equivalente, remitiendo ambas en definitiva a todo aquello que es llevado a cabo «por mandato del derecho común» ${ }^{2}$.

Una vez incorporada al constitucionalismo estadounidense, la jurisprudencia de su Corte Suprema fue dotando progresivamente a la expresión de un sentido específico, perfilándose -como veremos- más allá de este particular principio de legalidad para desarrollarse como una cada vez más concreta garantía frente al ejercicio arbitrario del poder. Paralelamente a esta evolución respecto a su contenido, que trascendía su inicial configuración en el derecho anglosajón, se produjo también una ampliación respecto a su ámbito de aplicación en lo que constituyó un lento proceso de nacionalización de la carta de derechos a partir de las reformas acometidas tras la guerra civil. $Y$ es que, hasta entonces, al igual que el resto de los derechos y garantías contenidos en el Bill of Rights constitucional, el debido proceso se encontraba circunscrito al ámbito federal, es decir, constituía exclusivamente una protección del individuo frente al poder federal, de manera que cualquier salvaguardia de carácter similar ante el ejercicio del poder de los Estados integrados en la Unión quedaba al amparo de lo que se estableciera -o no- en las constituciones estatales. Esto era difícilmente defendible en el contexto político de la posguerra civil, donde buena parte de la opinión pública consideraba que el ejercicio ilimitado e irresponsable del poder estatal había sido causa principal del enfrentamiento. La manera en la que el poder estatal desarrollase su acción afectando a la esfera de autonomía individual no podía seguir considerándose asunto ajeno a la federación pues sus disfunciones podían acarrear consecuencias intolerables desde la perspectiva de la moral pública, pero sobre todo porque -tal y como se había verificado- esas consecuencias se extenderían al ámbito de la economía y el comercio, poniendo en peligro la supervivencia de la federación. Consecuentemente, y en un clima de reforma constitucional de grandísimo calado, la garantía del debido proceso pasó a vincular a todos los Estados de la Unión mediante la aprobación de la Enmienda Decimocuarta. Su ratificación en 1868 incorpora un texto prácticamente idéntico al que de aplicación

2 Sobre los límites sustantivos derivados de la aplicación de la garantía del debido proceso en la Carta Magna, vid Keynes (1996, pp. 57-59). 
federal, pero añadiendo expresa mención al poder estatal: «ningún Estado privará a ninguna persona de vida, libertad o propiedad sin el debido proceso legal» iniciándose una lenta y laboriosa expansión de los derechos civiles por el territorio estadounidense. Un progresivo avance en el que la garantía del debido proceso tuvo y mantiene un especial protagonismo, de forma que se encuentra directamente vinculada con cada uno de sus hitos históricos. Desde las sentencias en favor de la igualdad racial ${ }^{3}$ tras la aprobación de la Ley de Derechos Civiles de 1964, pasando por el reconocimiento del derecho a la privacidad como límite a la injerencia legislativa en relación a los derechos reproductivos ${ }^{4}$, hasta las recientes decisiones sobre matrimonio igualitario -same-sex marriage- ${ }^{5}$, el debido proceso se ha revelado como el más poderoso y versátil argumento contramayoritario a disposición de la Corte Suprema en el ejercicio de su función de control del poder político en defensa de los derechos individuales.

El desarrollo jurisprudencial desde el debido proceso hasta el debido proceso sustantivo, parte del reconocimiento de que lo que deba ser el debido proceso en cada caso y dónde se fijen, por tanto, los límites a la acción de los poderes públicos respecto a los derechos individuales, es ciertamente una cuestión sustantiva que no puede resolverse mediante una remisión procedimental abierta ad infinitum. Y así, el procedimiento que ejecute tales actuaciones de injerencia en la esfera individual no ostentará per se el carácter de debido por el mero hecho de que se ajuste a un procedimiento legislativo previamente designado a esos efectos -un procedimiento que habría sido aprobado mediante una decisión anterior ajustada a un procedimiento de producción legislativa previamente designado a esos efectos-. La garantía del debido proceso no se corresponde con el principio del imperio de la ley, pues implica respecto al ejercicio de los poderes públicos en su conjunto un control sustancial que carecería de contenido efectivo si no abarcara al poder legislativo ${ }^{6}$.

Esta afirmación, que podría concitar dudas desde la perspectiva del derecho continental, se entiende con más claridad a la vista del desarrollo histórico de la garantía, tal y como la hemos referido. Así, la vinculación del monarca con el debido proceso entendido como law of the land, es decir, derivado del mandato del derecho común anglosajón, implicaba esencialmente la mediación de un contrapoder al derivar dicho mandato de un origen distinto al de la propia Corona. De este modo, y esta cuestión es clave, no es que la Corona se encontrara vinculada a sus propios procedimientos, dado que éstos le eran ajenos en tanto en cuanto su establecimiento y modificación no se encontraban a su alcance. Este es el aspecto esencial del debido proceso en su perspectiva histórica: que remite el problema de la fundamentación del poder -que en Europa se iría asentando hasta la caída del Antiguo Régimen en la

\footnotetext{
${ }^{3}$ Particularmente Loving v. Virginia, 388 U.S. 1 (1967) que en virtud de las cláusulas del debido proceso e igual protección ante la ley invalidaba la ley segregacionista del Estado de Virginia que prohibía (al igual que otros 16 Estados en ese momento) los matrimonios interraciales.

${ }^{4}$ Griswold v. Connecticut, 381 U.S. 479 (1965) que en virtud del derecho a la privacidad protegido por la cláusula del debido proceso, invalidaba la prohibición legislativa estatal contra la prescripción, venta o uso de anticonceptivos, incluso entre parejas casadas; Eisenstadt v. Baird 405 U.S. 438 (1972) que establecía por las mismas razones ese mismo derecho para parejas no casadas; y Roe v. Wade 410 U.S. 113 (1973) declarando que el derecho a la privacidad comprendía el derecho fundamental de la madre a decidir si quería terminar o no con su embarazo de forma que un Estado no podía interferir en dicha decisión sin mediar un interés legítimo -compelling interest-para su regulación.

5 United States v. Windsor, 570 U.S. 744 (2013) y Obergefell v. Hodges, 576 U.S. (2015), ambas basadas en las cláusulas del debido proceso e igual protección ante la ley.

${ }^{6}$ La cuestión se expone por la Corte Suprema estadounidense al señalar en relación al debido proceso que «it is manifest that it was not left to the legislative power to enact any process which might be devised. The article is a restraint on the legislative as well as on the executive and judicial power of the Government, and cannot be so construed as to leave Congress free to make any process 'due process of law' by its mere will». Murray's Lessee v. Hoboken Land \& Improvement Co., 59 U.S. 272 (1856). Opinion of the Court.
} 
figura del monarca como único punto de partida-, a un punto de fuga de carácter consuetudinario y, por tanto, no-absolutista. $Y$ es precisamente en este sentido noabsolutista que debe entenderse la garantía del debido proceso al mediar en los procedimientos democráticos. Es decir, como un instrumento de contrapoder que sustrae de la sede desde la que se origina el poder político el control de la legitimidad de sus procedimientos, algo que en democracia se traduce con carácter necesariamente contramayoritario.

Ahora bien, antes de concretar el principio que fundamenta esta garantía, permítaseme recordar que a la hora de tratar con el pensamiento jurídico del common law los juristas de formación continental debemos actuar con prudencia dado que, al igual que ocurre -por ejemplo- con el dominio de una segunda lengua, el derecho comparado requiere volver a pensar conceptos supuestamente conocidos, esta vez desde diferente perspectiva. Tanto los prólogos de los manuales de derecho comparado como los de teoría de la traducción, nos advierten de la necesidad de tener en cuenta que las expresiones conocidas que son resultado del progresivo decantado de una concreta tradición nunca admiten una traducción directa más que aproximada. Son siempre formas históricamente situadas de resolver los mismos problemas en diferentes contextos, y por lo tanto, no serán nunca completamente asimilables.

Parece necesaria esta advertencia dada la intrínseca relación que la garantía del debido proceso mantiene con el principio general de la interdicción de la arbitrariedad del poder político, del que dicha garantía es instrumental. Y así, aunque este principio tiene ecos reconocibles en el derecho continental y español, se trata de una aproximación al problema sustancialmente diferente. Como es lógico, y tratándose de un contexto jurídico anglosajón, la interdicción de la arbitrariedad no se formula en el constitucionalismo estadounidense de manera abstracta, sino referida en concreto: primariamente a aquellos casos en los que del ejercicio del poder institucional pueda derivarse un riesgo sustancial para la vida, propiedad, o libertad de los individuos. Es importante subrayar ese carácter sustancial, puesto que al no derivarse de una interdicción de carácter general, la formulación de la garantía en términos concretos requiere del operador que efectúe prima facie una especie de juicio de relevancia implícito: no cualquier actuación del poder político estará sometida a las exigencias del debido proceso legal, sino primariamente aquellas actuaciones que supongan o puedan acarrear literalmente una privación -es decir, una afectación sustancial- de la vida, propiedad o libertad.

Ninguna garantía constitucional tiene valor en sí al margen de lo que constituye su finalidad o fundamenta, de manera que inicialmente cualquier aproximación jurisprudencial a la garantía suele referirse en primer lugar a su principio, al objeto de delimitar preliminarmente su significado. Esta delimitación preliminar es de suma importancia, pues sienta la guía y los parámetros que deberían conducirnos a lo largo del posterior desarrollo jurisprudencial. $Y$ en este sentido, una de las primeras exposiciones jurisprudenciales del principio de interdicción de la arbitrariedad del poder político explícitamente en relación con la garantía de la cláusula constitucional del debido proceso, se encuentra en Hurtado v. California (1884). En esta resolución la Corte Suprema declara con rotundidad que el proceso debido de la ley no sólo presupone que (1) la voluntad del poder político deba someterse a los formalismos que comporta su expresión reglada, sino que (2) sustancialmente requiere la ausencia de arbitrariedad. El ejercicio arbitrario del poder, «ya se manifieste como el decreto 
de un monarca personal o el de una multitud impersonal» nunca será ley, al no ajustarse a su debido proceso ${ }^{7}$.

El análisis de las condiciones requeridas por la garantía del debido proceso mediante la distinción de dos momentos lógicos, por una parte el sometimiento de la voluntad del poder político mediante una expresión altamente formalizada -susceptible por sí misma de excluir su ejercicio arbitrario según las circunstancias-, y por otra, la exigencia de una justificación efectiva que excluya dicha arbitrariedad más allá del cumplimiento de dichos formalismos, es ilustrativa, aunque sea de modo esquemático, de los dos aspectos -procedimental y sustantivo- mediante los que el debido proceso se ha desarrollado en la jurisprudencia de la Corte Suprema estadounidense. Esta doble vertiente del debido proceso fue descrita por el Juez Presidente Rehnquist con una fórmula ya clásica:

By requiring the government to follow appropriate procedures when its agents decide to "deprive any person of life, liberty, or property" the Due Process Clause promotes fairness in such decisions. And by barring certain government actions regardless of the fairness of the procedures used to implement them [...] it serves to prevent governmental power from being "used for purposes of oppression".

Así, mientras el proceso debido procedimental -procedural due process-es la vertiente de la garantía que atiende posibles vulneraciones de procedimiento en ámbitos de ejercicio del poder altamente formalizados, tales como el judicial y el administrativo, el llamado proceso debido sustantivo -substantive due process - se refiere al escrutinio constitucional que impondría esta garantía en relación al ejercicio del poder que, adicionalmente al cumplimiento de los preceptivos formalismos preestablecidos, precise de una justificación razonable más o menos expresa en relación con derechos individuales tales como la intimidad -privacy-, o la libertad de expresión -freedom of speech-, entre otros. Esta justificación adicional superpuesta a la justificación que con carácter abstracto comporta intrínsecamente la regla de procedimiento, decimos que tiene valor sustantivo porque es concreta, aunque en realidad cualquier formalismo con valor jurídico ya incorpora necesariamente valores sustantivos. Así, a pesar de que la formalización tiene por objeto garantizar la razonabilidad de la actuación, y por lo tanto del resultado, lo razonable no puede en todos los casos circunscribirse a los límites que se deducen de una definición operativa formal. Los sistemas jurídicos -como cualquier sistema coherente- se fundamentan en postulados, es decir, elementos axiomáticos que expresan juicios para casos abstractos formalizados mediante normas, reglas o procedimientos, que precisamente por no necesitar demostración en cada caso, pueden no ajustarse en concreto a los criterios de razonabilidad que abstractamente se les presuponen. Y por eso es necesario en determinadas ocasiones una justificación superpuesta, pues tal y como señala la Corte Suprema, la cláusula del debido proceso no es sólo garantía de un proceso justo, y la libertad que protege incluye algo más que la ausencia de limitación física ${ }^{9}$.

\footnotetext{
${ }^{7}$ «It is not every act, legislative in form, that is law. Law is something more than mere will exerted as an act of power [...] and thus excluding, as not due process of law, acts of attainder, bills of pains and penalties, acts of confiscation, acts reversing judgments, and acts directly transferring one man's estate to another, legislative judgments and decrees, and other similar special, partial and arbitrary exertions of power under the forms of legislation. Arbitrary power, enforcing its edicts to the injury of the persons and property of its subjects, is not law, whether manifested as the decree of a personal monarch or of an impersonal multitude». Hurtado v. California, 110 US 516 (1884), Opinion of the Court.

${ }^{8}$ Daniels v. Williams, 474 U.S. 327 (1986). Opinion of the Court.

${ }^{9}$ Washington v. Glucksberg, 521 U.S. 702 (1997). Opinion of the Court.
} 
En atención a esta idea de justificación adicional según los casos, la legislación adoptada conforme al procedimiento de producción legislativa preestablecido podrá someterse a diversos niveles de escrutinio, según su contenido. Y así, en la mayoría de supuestos la legislación conservará su presunción de constitucionalidad siempre que se muestre como un instrumento concebiblemente racional orientado a un fin legitimo del gobierno, es decir, se establecerá un nivel mínimo de escrutinio - rational basis review- dado que los procesos políticos comportan en el cumplimiento de sus formalismos un nivel suficiente de justificación. Sin embargo, el nivel de exigencia en cuanto a la justificación del contenido se elevará al máximo cuando el mismo afecte a derechos fundamentales de individuos o minorías, o en palabras de la Corte Suprema, cuando tales procesos políticos -diseñados para dar expresión a la voluntad de la mayoría- puedan dañar a «minorías discretas e insulares» ${ }^{10}$.

2.2. El debate doctrinal acerca de la supuesta imposibilidad lógica de lo procedimental-sustantivo

Esta aproximación jurisprudencial al problema de la interdicción de la arbitrariedad del poder político ha generado a lo largo de los últimos cincuenta años gran controversia en Estados Unidos sobre cuestiones fundacionales respecto a la democracia liberal. El Ilamado activismo judicial, la legitimidad del control judicial de la constitucionalidad de las leyes y la correcta definición de sus límites, así como -en última instancia- el diseño institucional de la democracia constitucional, son algunos de los temas que abarca la amplísima producción doctrinal sobre la garantía del debido proceso. Y así, la vertiente sustantiva de la garantía ha sido puesta en cuestión por un importante sector de la doctrina constitucionalista que considera que el proceso debido sustantivo es un artificio -en el sentido de que se trataría de una construcción jurisprudencial no sustentada de ningún modo en el texto constitucional-, cuya única virtualidad consistiría en vulnerar los límites de la función judicial en un afán por imponer valores y visiones particulares del mundo no refrendadas por los legítimos poderes democráticos expresados mediante mayorías legislativas.

Si bien este asunto ha sido abordado críticamente desde perspectivas muy diversas, existe un particular argumento de carácter lógico-semántico, posteriormente apropiado desde posiciones textualistas y originalistas, que se ha extendido como lugar común del pensamiento legal estadounidense, a pesar de que consiste en la reiteración de un viejo malentendido filosófico pobremente adaptado a la problemática jurídica que nos ocupa, y que constituye un claro ejemplo de la falaz reificación del pensamiento abstracto al que hacíamos referencia al comienzo de este trabajo. Popularizado por John Hart Ely en su Democracy and Distrust, el argumento en cuestión expone, en el que se considera uno de los más prestigiosos ensayos del moderno constitucionalismo norteamericano, la imposibilidad lógica de que una garantía procedimental sea al mismo tiempo sustantiva ${ }^{11}$. Tratar el debido proceso como una cláusula de contenido sustantivo implicaría no distinguir entre la noción básica que establece la diferencia entre el qué y el cómo, entre medios y fines. La referencia al proceso en la cláusula constitucional es clara, excluyendo a riesgo de caer en contradicción cualquier enjuiciamiento sustantivo. Expresando un evidente

\footnotetext{
10 El criterio por el cual la revisión constitucional de la legislación debe establecerse mediante diversos niveles de escrutinio, según los casos, se recoge en la célebre nota a pie de página número cuatro de la United States v. Carolene Products Co., 304 U.S. 144 (1938).

${ }^{11}$ Existen al menos tres referencias anteriores de este argumento: W. F. Bowker en 1956, Leonard Levy en 1966, y Hermine Herta Meyer en 1977. Para más detalles, vid. Greene (2016, pp. 270-271).
} 
tono de desagrado e impaciencia hacia aquellos que no aceptan la obviedad de este argumento, Ely (1980, p. 18) señala que

es un poco embarazoso sugerir que un texto es informativo cuando tantos desde hace tanto, lo han encontrado evocativo, pero no hay manera de obviar el hecho de que la palabra que sigue a "debido" es "proceso" [...] aparentemente nos encontramos en la obligación de recordar periódicamente que "proceso debido sustantivo" es una contradicción en sus propios términos -del tipo "la rojez del verde pastel"-.

En esta línea, el Juez de la Corte Suprema Antonin Scalia, uno de los más destacados críticos del debido proceso sustantivo, ha utilizado este argumento lógicosemántico en numerosas ocasiones, refiriéndolo tanto en resoluciones judiciales como en su producción académico-doctrinal en concordancia con su textualismo interpretativo, según el cual toda interpretación debe producirse del modo semánticamente más preciso posible, dedicando especial atención a las reglas sintáctico-gramaticales, lo que a su juicio minimizaría la discrecionalidad interpretativa judicial y su influenciabilidad respecto a contextos sociales, políticos o morales (Kannar, 1990) calificando al debido proceso sustantivo lisa y llanamente como un oxímoron ${ }^{12}$. Scalia (1997, pp. 24-25) deriva de este argumento -y en concreto de la pretensión de que lo procedimental excluye lo sustantivo- una interpretación del debido proceso que textualmente excluiría cualquier uso o interpretación sustantiva del mismo, pues esta cláusula

en virtud de sus ineludibles términos, sólo garantiza el proceso. Podemos ser privados por el Estado de la propiedad, de la libertad, e incluso de la vida, pero no sin el debido proceso que nuestras tradiciones requieren -particularmente, una ley válidamente promulgada y un juicio justo-. Afirmar lo contrario es abandonar el textualismo y convertir textos adoptados democráticamente en trampolines para la producción legislativa judicial.

Este argumento, estrictamente en su carácter lógico-semántico, se ha percibido provisto de gran solidez por la práctica unanimidad de la doctrina constitucionalista estadounidense. $Y$ en este sentido lo expresa el profesor Jamal Greene, cuando afirma que se ha extendido a lo largo de todo el espectro ideológico la idea de que un análisis textual respecto al debido proceso sustantivo es imposible, dado que la formulación de dicha garantía en esos términos constituiría efectivamente un uso impropio o abusivo de la lengua inglesa (Greene, 2016, p. 254).

Esta es la razón por la que, en el debate doctrinal que pretende elucidar la congruencia del proceso debido sustantivo como construcción jurisprudencial, así como la posibilidad de su legítima correspondencia con el contenido de la cláusula del proceso debido, la cuestión que ahora apuntamos no se analice por sus propios méritos -es decir, en su carácter lógico-semántico-, sino que, lo usual sea que, o bien se ignore, o bien se aborde mediante aproximaciones indirectas. $Y$ esto, a pesar de que si dicho argumento se confirmara por su propio carácter mediante un análisis de fondo, muy probablemente habría que concluir en un mandato constitucional directo contrario al uso substantivo de la garantía, derivado de esa literalidad ineludible a la que se refieren los textualistas.

Pero en realidad los textualistas, contrarios a la vertiente substantiva de la garantía, llevan décadas considerando suficiente demostración en este sentido haberse limitado a remarcar lo que entienden la consecuencia lógica de una aparente obviedad: la relación contradictoria entre el fondo y la forma. Ahora bien, si analizamos la cuestión con el debido detenimiento, observaremos que esta supuesta obviedad se

12 U.S. v. Carlton 512 U.S. 26 (1994), (Scalia, J., concurring). 
fundamenta en un falso sobreentendido procedente de determinados usos del lenguaje ordinario que confunden lo opuesto con lo contradictorio, hasta presuponer la identidad de ambos términos cuando en el fondo tratan de la expresión de relaciones bien distintas. Así, mientras que la contradicción implica relaciones lógicas de carácter mutuamente excluyente -algo que se da con mucha frecuencia en los diferentes lenguajes de manera abstracta, pero nunca en la realidad concreta-, la relación de oposición se basa en una diferencia de grado. El tratamiento superficial de esta cuestión ha derivado por parte de este sector doctrinal en posturas que encuentran muy difícil justificación si aspiran a mantener la coherencia con su planteamiento inicial. Y así, por ejemplo, el propio Juez Scalia habría reconocido que la cláusula del debido proceso sí incorpora ciertas garantías sustantivas «a pesar de su textual limitación al procedimiento» ${ }^{13}$. Es decir, que la cláusula del debido proceso presupone ciertas garantías substantivas al tiempo que las excluye, una afirmación que sí podríamos calificar de contradictoria.

Por otro lado, el sector doctrinal opuesto, favorable al proceso debido sustantivo, adolece de la misma falta de rigor en relación a esta cuestión en concreto. Así, a pesar de haber acusado recibo de esta crítica de carácter lógico-semántico, no la ha rebatido sino acudiendo a una argumentación indirecta. Es decir, no abordando la cuestión en sí, sino considerándola como si se tratara de una especie de juego de palabras, una anomalía del lenguaje que no aportara nada sustancial al debate. Un asunto menor que pudiera combatirse simplemente ignorándolo para seguidamente desarrollar otras vías de razonamiento que sí abarcasen cuestiones supuestamente de fondo, en el entendimiento de que así se estaría rebatiendo in totum el argumento de contrario.

Paradigmáticos de este tratamiento indirecto, destacan los trabajos de L. H. Tribe. A pesar de no acometer directamente el problema al despacharlo como cuestión semántica ${ }^{14}$, el profesor Tribe ha puesto de manifiesto que los preceptos constitucionales, incluso los de carácter procedimental, precisan del desarrollo de una teoría de derechos fundamentales que asegure su adecuada comprensión y aplicación. $Y$, más fundamentalmente, ha señalado que para establecer si en un determinado contexto es preciso acudir a un procedimiento jurisdiccional -adjudicative process- o por el contrario a uno de representación política -representative process - no podemos tratar la cuestión como si se tratara solo de una cuestión técnica relativa a cómo de eficazmente pueden los diferentes procedimientos reflejar los intereses en juego, sino que es necesario tener en cuenta el carácter e importancia de esos intereses. Es decir, una cuestión de carácter sustantivo relativa a una teoría de valores y derechos (Tribe, 1980). El valor de un procedimiento constitucional no puede derivarse de su aptitud como un medio para un fin independiente de aquel, sino que es necesario reconocer que el proceso tiene un valor intrínseco que debe concordar con su finalidad, y así, por ejemplo, ser oído no es sólo instrumental a un fin, sino que es parte de lo que significa ser una persona, de manera que «el proceso en sí deviene, por lo tanto, sustantivo» (Tribe, 1980, pp. 1070-71). Tribe expone una idea que podríamos formular mediante estas dos simples proposiciones: (1) los procedimientos en sí no significan nada si no se encuentran contextualmente vinculados a determinados valores sustantivos, y (2) los

\footnotetext{
${ }^{13}$ TXO Production Corp. v. Alliance Resources (92-479), 509 U.S. 443 (1993), (Scalia, J. with Thomas, J. concurring).

14 "Some commentators have called "substantive due process" a contradiction in terms. But a dismissal on semantic grounds of the very notion of substantive due process is unwarranted». Tribe (2000, p. 2569).
} 
procedimientos constitucionales sí tienen significado, porque si no serían incomprensibles y, por lo tanto, inaplicables ${ }^{15}$.

Es evidente que Tribe pretende ofrecer una respuesta sólo jurídica a un problema que se plantea inicialmente en términos estrictamente lógicos y semánticos. Es decir, no responde a la pregunta acerca de cómo es posible decir "procedimental sustantivo" sin incurrir en contradicción, sino que se limita a demostrar que el derecho, por su propio carácter, parece funcionar así. Esto es algo que explícitamente reconoce el propio Tribe al manifestar la defensa de sus argumentos al margen de «cualesquiera dificultades lingüísticas» (Tribe, 1997, p. 85) que pudieran suscitarse para entender que la frase "debido proceso legal" incorpora límites sustantivos. 0 cuando, en respuesta a la crítica de Ely señalando que no hay manera de obviar el hecho de que la palabra que sigue a "debido" es "proceso", Tribe pasa por alto la implicación de contradicción y se limita a añadir que, si bien Ely estaría en lo cierto, "las palabras que siguen a "debido proceso" son "de la ley", y la palabra "ley" parece haber sido el punto de partida textual para el debido proceso sustantivo» (Tribe, 1980, p. 1066).

Abordando el asunto más directamente, aunque todavía sin tratar la cuestión en su necesario carácter multidisciplinar, Frank $\mathrm{H}$. Easterbrook es de los pocos autores que han señalado que no es posible realizar un análisis adecuado de esta garantía constitucional sin entender previamente que sustancia y proceso son partes de un mismo fenómeno (Easterbrook, 1980, p. 85). Así, el tipo de procedimiento que sea debido en cada momento variará según el juicio que la Corte lleve a cabo en relación a una cuestión sustantiva: la importancia de los intereses en juego. A mayor interés, afirma Easterbrook, en mayor grado importarán a los interesados los posibles errores, de manera que cuanto más importen, más estará dispuesta la sociedad a invertir para prevenirlos. Esa mayor necesidad se traducirá en una mayor exigencia constitucional en relación a los procesos relacionados con esos vitales intereses (Easterbrook, 1980, p. 89).

En palabras de Jamal Greene, el proceso debido sustantivo ha sido considerado como una contradicción textual pese a que en realidad es una expresión redundante. Cualquier juicio en orden a establecer si un determinado proceso es o no debido, no puede ser indiferente a cuestiones sustantivas: el debido proceso comporta una regla o criterio de razón de carácter sustantivo en orden a calibrar la relación entre, de una parte, la naturaleza y la finalidad de la privación, y de otra, el proceso conforme al que se lleva a cabo (Greene, 2016, pp. 253-254). Sin embargo, a pesar de esa implicación necesaria que se ha traducido efectivamente en la praxis jurisprudencial de la garantía del debido proceso sustantivo, se ha aceptado la idea de que textualmente ambos términos implicaban contradicción, conformando lo que Greene denomina meme constitucional. Siguiendo a Dawkins (1976), con el término meme Greene quiere expresar un elemento cultural -ya sea una idea, una palabra, o un conjunto de suposiciones- cuyo crecimiento y evolución se dice que primordialmente tiene lugar mediante transmisión genética. Es decir, un meme sería una idea o un paquete de información, tan profundamente embebido en nuestra cultura, que a pesar de ser reproducido sin una debida demostración o acompañándose de una posterior elaboración, se le entiende inmune a cualquier argumentación en contrario.

\footnotetext{
${ }^{15}$ A pesar de su aproximación indirecta, Tribe aborda el asunto esencial pues de su exposición se deducen implicaciones éticas situadas en el nudo del problema de lo procedimental-sustantivo y que tienen que ver con el carácter situacional de los elementos que integran los pares fin-medios, materiaforma, o procedimental-sustancial.
} 
Ahora bien, para Greene la existencia de estos memes es necesaria, dado que cumplen una función retórica necesaria en la argumentación de los operadores jurídicos. Sin embargo -y a pesar de que no podemos estar más de acuerdo en que, efectivamente, la argumentación jurídica no se encuentra orientada a la demostración de una verdad absoluta, sino a la persuasión-, la retórica no es una técnica al servicio de la confusión promovida desde el interés particular, sino todo lo contrario. Ya se utilice en un contexto jurídico, o en cualquier otro, la retórica tiene como finalidad establecer las bases para una comprensión de la realidad compartida que haga posible la convivencia a través de un encadenado proceso de acuerdos por el que se ajusten principios abstractos a las situaciones concretas que comportan un conflicto entre intereses. Lógicamente, cada uno de esos acuerdos no tiene lugar en un periodo de tiempo infinito, sino que es llevado a cabo razonablemente según las exigencias de cada caso.

Las limitaciones contextuales conllevan que la persuasión no persiga el mejor de los argumentos posibles en el mejor de los mundos posibles, sino que debamos contentarnos con un argumento razonablemente aceptable. Es decir, que funcione para el caso en cuestión dadas las circunstancias en las que se expone y discute. Es en este sentido que podemos entender que los memes son de gran utilidad, pues nos proveen de atajos retóricos en nuestra argumentación al constituir hitos compartidos. Es decir, puntos de acuerdo razonable, que aunque limitados sustantivamente, sirvan estratégicamente a la persuasión y al compromiso. Ahora bien, ese acuerdo derivado de la persuasión retórica tendrá bases más firmes si su comprensión obedece a criterios dotados de la máxima coherencia interna posible, dadas las circunstancias. Y en este sentido, en una sociedad culturalmente avanzada, no cualquier meme será adecuado. En el caso del proceso debido sustantivo, el meme constitucional que reproduce la idea de que el proceso sustantivo implica una contradicción textual nos parece lógicamente insostenible y por esa razón comporta más impedimentos que ventajas, de manera que nos resulta adecuada la propuesta del profesor Greene para desmontarlo al desvelar las inconsistencias jurídicas que implica ${ }^{16}$. Ahora bien, creemos que Greene no aborda la raíz del problema, pues no lo acomete en su carácter lógico-semántico. Es decir, demostrando la posibilidad lógica de lo procedimental-sustantivo desde el análisis de la pretendida contradictio in adjecto o contradicción semántica entre ambos términos.

En este sentido, y antes de abordar el asunto desde su perspectiva lógicosemántica, debemos aclarar una cuestión previa. La figura retórica del oxímoron puede formarse mediante el uso de contrarios o mediante opuestos. Decir triangulocuadrado es un tipo de oxímoron que implica necesariamente contradicción, dado que los términos cuadrado y triangulo obedecen a construcciones abstractas que no admiten gradación. Sin embargo, azul-amarillo no implica contradicción sino una relación de contrariedad al involucrar opuestos que pueden combinarse. $Y$ esta no es una cuestión novedosa: los debates que pretenden elucidar la relación procesal/sustantivo se remontan a más de dos mil años, reproduciéndose repetidamente en diversos ámbitos del conocimiento como si en cada ocasión se estuviera expresando un problema nuevo.

Así, tras esta primera exposición del problema desde el punto de vista jurídico, en la que hemos considerado que los debates en relación con el proceso debido sustantivo eran particularmente ilustrativos, pasamos a un segundo planteamiento de la misma cuestión. Pero esta vez desde su carácter propiamente lógico-semántico,

\footnotetext{
${ }^{16}$ «Constitutional memes are entrenched -indeed, are self-reinforcing- but they are not permanent. [...] Substantive due process might not always be thought incompatible with the constitutional text, and indeed this Essay can be understood, in part, as a step towards that end». (Greene, 2016, p. 294).
} 
mediante lo que denominaremos adjetividad sustantiva, algo que nos acercará al pensamiento aristotélico y al nacimiento de la retórica.

\section{Aproximación desde la filosofía: adjetividad sustantiva}

A la hora de representar la realidad, el discurso racional se despliega simultáneamente en dos sentidos: (1) conceptual-sustantivamente, expresando los elementos de la realidad significándolos (es decir, dotándolos de sentido particular al asignarles un signo) al objeto de representarlos presentificadamente en una imagen fija; y (2) procesual-adjetivamente, representando dinámicamente y estableciendo las relaciones entre aquellas unidades fijas de significante-significado.

Cuando afirmamos, por ejemplo, que «un sujeto se define mediante todos los adjetivos que pueden aplicársele válidamente» o que "un objeto cualquiera es el conjunto de sus relaciones para con otros objetos», estamos haciendo referencia a esta idea de representación dual de la realidad mediante el uso de sustantivos y adjetivos como expresión pragmática de los conceptos de materia y forma. Los adjetivos nunca se predican absolutamente sino en relación con algo, es decir, situacionalmente. De esa manera, solemos entenderlos en relación a un objeto porque sobreentendemos su relación con un contexto más amplio, compuesto de otras relaciones. El contexto dota de sentido al adjetivo. De ahí que digamos que un proceso o una relación tiene carácter adjetivo entendido aisladamente en cuanto tal proceso o relación, mientras que si lo consideramos en conexión con otros procesos o relaciones, su carácter será sustantivo.

Este modo dual de descomponer nuestro pensamiento fue expuesto por Aristóteles subrayando su naturaleza racional-discursiva, y la descripción de su funcionamiento ha comportado desde entonces una potente herramienta analítica aplicable a todos los aspectos de la realidad representada mediante ese pensamiento, es decir, a todo lo concebible. La teoría aristotélica de la materia y la forma es superadora de la idea de un mundo contradictorio y en permanente movimiento, y se complementa mediante la utilización de categorías que constituyen criterios de razón que apelan al fundamento -o esencia- de las cosas mismas. Sin embargo, el desarrollo histórico de esta herramienta ha aparejado el asentamiento de una tradición esencialista que ha pretendido la búsqueda de certezas imposibles mediante una separación entre lo sustantivo y lo procedimental excesivamente nítida, distorsionando la relación adjetivo/sustantivo, una relación que es intrínsecamente dinámica, hasta el punto de ignorarla casi por completo. Esta tradición esencialista, cuyo desarrollo histórico y sus causas no rastrearemos aquí, se encuentra tan arraigada que nos resulta natural, por ejemplo, que la enseñanza de la gramática de la lengua describa sustantivos y adjetivos como realidades completamente diferenciadas, ocultando el hecho de que la sustantivación siempre se produce a través de la asimilación a una unidad conceptual fija con valor pragmático (es decir, con utilidad en un contexto concreto) de cadenas adjetivas complejas, o dicho en otras palabras: que todo sustantivo se compone y se descompone en un conjunto de expresiones adjetivas solidificadas en torno a un criterio de razón contextualmente relevante. Cada sustantivo en cuanto ente contiene una serie de cadenas adjetivas que le refieren esencialmente, es decir, que se le predican per se -en terminología aristotélica-, de manera que comportan el núcleo de su definición. Ahora bien, toda delimitación sustantiva requiere señalar qué adjetivaciones son relevantes y cuáles no, lo que implica un posicionamiento previo respecto a lo real, -un posicionamiento que no es neutral-.

Como suele decirse, la adjetivación no es neutra. Lo que ocurre es que esa expresión suele referirse al empleo de un adjetivo sobre un sustantivo ya formado (es 
decir, al que se le ha asignado su forma que ya le es propia). Sin embargo, lo destacable es que la adjetivación nunca es neutra, especialmente la que compone cada sustantivo en su estructura interna. Así, en un clásico ejemplo, Hombre se descompone en la cadena animal + racional y no en otras alternativas tales como animal + bípedo + implume, precisamente porque la línea de demarcación que constituye el juicio de razón que delimita el concepto es la característica ser-racional, y no otra. Y esa decisión no es neutral.

Para entender mejor el carácter de esta transducción de componente axiológico entre lo adjetivo y sustantivo, puede resultar interesante acudir en el nivel gramatical a la descripción ficticia que Jorge Luis Borges hace de Tlön, un mundo imaginario en el que se renuncia a otorgar un valor intrínseco a ningún tipo de cadena adjetiva, de manera que en sus lenguas no existen los sustantivos. El lenguaje de Tlön no se encuentra connotado por la primacía de ningún criterio de razón que, en un determinado contexto, suponga la elección de un valor sobre otro. Las cosas se representan como un conjunto de relaciones adjetivas puestas de manifiesto por el hablante, nunca por el propio lenguaje, de manera que dichas expresiones carecen lingüísticamente de significado objetivo. Y así, en su hemisferio austral el lugar del sustantivo es ocupado por «verbos impersonales, calificados por sufijos (o prefijos) monosilábicos de valor adverbial. Por ejemplo: no hay palabra que corresponda a la palabra luna, pero hay un verbo que sería en español lunecer o lunar. Surgió la luna sobre el río se dice hlör u fang axaxaxas mlö o sea en su orden: hacia arriba (upward) detrás duradero-fluir luneció. (Xul Solar traduce con brevedad: "upa tras perfluyue lunó". Upward, behind the onstreaming it mooned.) [...] En los del hemisferio boreal [...] la célula primordial no es el verbo, sino el adjetivo monosilábico. El sustantivo se forma por acumulación de adjetivos. No se dice luna: se dice aéreo-claro sobre oscuro-redondo o anaranjado-tenue-del cielo o cualquier otra agregación» (Borges, 1971, pp. 21-22). Como cada hablante establece su propia sustantivación al no existir criterios comunes, todos los nombres son metáforas (es decir, para generar la sustantivación presuponen la elección de criterios de razón que no pueden calificarse de razonables, pues carecen de valor intersubjetivo). Esa absoluta neutralidad del lenguaje en Tlön, que lo lleva a desvincularse por completo de cualquier contexto posible -y por lo tanto de la realidad misma-, puede resumirse en la siguiente sentencia: «el hecho de que nadie crea en la realidad de los sustantivos hace, paradójicamente, que sea interminable su número» (Borges, 1971, p. 22).

Lo dicho hasta aquí nos permite retomar el problema desde el punto de vista jurídico, señalando que la réplica más pertinente -y por tanto más eficaz- frente a los que aspiran a conceptualizar los procedimientos constitucionales desvinculados de su componente axiológico no consiste solamente en demostrar que el derecho no admite esta posibilidad, es decir, hacer lo que se ha hecho hasta ahora: afirmar que el derecho no funciona así, aun a pesar de la incongruencia textual-aparentemente inexplicable- de la expresión proceso sustantivo.

Si pretendemos zanjar la cuestión debemos demostrar porqué el derecho no funciona así. Para ello, tal y como venimos diciendo, es necesario afrontar el problema en sus justos términos: el de la relación expresada mediante los pares procedimental/sustancial o adjetivo/material. Esos términos de oposición configuran una relación que es la misma en cada disciplina o ámbito del conocimiento, y que ha sido descrita desde los textos aristotélicos hasta los del segundo Wittgenstein, repitiendo siempre un esquema fundamental que puede revelarse mediante comparación interdisciplinar. Aquí, por una evidente limitación de espacio, nos centraremos sólo en dos aproximaciones adicionales que creemos serán suficientes para mostrar la identidad que subyace en la diversidad de estos enfoques. 
4. Aproximación desde la Ciencia Cognitiva y la inteligencia artificial simbólica: la inteligencia como un entramado de sistemas de reglas

La Ciencia Cognitiva tiene por objeto describir las relaciones entre mente y cerebro, y en última instancia establecer una definición de ambas. Esta ciencia se desarrolla a partir de los trabajos de Newell y Simon, y particularmente en base a su Hipótesis del Sistema de Símbolos Físicos (Newell y Simon, 1976), según la cual toda acción y conducta inteligente puede ser necesaria y suficientemente descrita y explicada por símbolos y sus reglas operativas que tendrán también forma simbólica o formalizada, siendo así que tales reglas y símbolos serán dadas dentro de todo sistema del que se predique acción o conducta inteligente.

En definitiva, la Ciencia Cognitiva y su subdisciplina, la Inteligencia Artificial Simbólica (dedicada a la representación computacional de los sistemas de símbolos físicos), pretenden la descripción formalizada de la inteligencia a través del análisis de sus procesos. Esta pretensión de que el pensamiento pueda reproducirse solo mediante el concurso de procesos computacionales, equiparando así pensamiento y computación, implica presuponer necesariamente cierta permeabilidad entre los niveles sintáctico y semántico. Y justo esta cuestión se encuentra en el núcleo del problema planteado por la llamada Inteligencia Artificial Fuerte ${ }^{17}$ al afirmar que de verificarse supondría no sólo inteligencia sino el surgimiento de conciencia y consciencia.

A partir de los referidos objetivos se ha desarrollado un debate académico que nos resulta pertinente al replantear problemáticamente -como si se tratara de algo novedoso- la relación formal/material en términos muy parecidos a los hasta aquí expuestos. El comienzo de esta controversia se sitúa en la publicación por John Searle en 1980 de Minds, Brains and Programs, donde el célebre filósofo del lenguaje pone en cuestión la posibilidad de formalizar la inteligencia mediante su asimilación a procesos computacionales, impugnando por tanto el concepto de Inteligencia Artificial Fuerte al aseverar que para deducir la existencia de inteligencia, conciencia y consciencia, no es en sí mismo suficiente haber constatado que para un determinado sistema se siguen reglas. Para apoyar esta afirmación, Searle (1980) propuso un argumento que denominó experimento mental de la habitación china. Imaginemos una habitación en la que se encuentra encerrado el propio Searle con una lista de símbolos en chino - un idioma que desconoce- $y$ unas instrucciones en un idioma que sí entiende por las que se relacionan esos símbolos chinos en razón de su forma, de manera que para cada símbolo o cadenas de símbolos existe una respuesta, es decir, otro símbolo o cadena de símbolos en chino. Searle no entiende la pregunta ni la respuesta, pero sí entiende las instrucciones -o programa- de manera que puede «responder» mecánicamente conectando pregunta con respuesta sólo por razón de su forma. Le van llegando mensajes en chino que él contesta al relacionar el símbolo que se le entrega con su respuesta predeterminada en la lista. Imaginemos ahora que Searle pasase suficiente tiempo encerrado en la habitación y adquiriese mucha práctica relacionando preguntas y respuestas, de manera que siempre devolviera la respuesta correcta en un intervalo corto de tiempo. Para ese caso, cualquier persona situada en el exterior de la habitación que sí entendiera el chino y pretendiese comunicarse con él mediante ese sistema de envío de mensajes podría llegar a pensar que nuestro filósofo sí entiende chino. Pues bien, continua Searle, esto es lo

\footnotetext{
${ }^{17}$ La inteligencia artificial fuerte (Artificial General Intelligence) es una hipótesis que se verificaría al constatarse que una maquina puede llevar a cabo cualquiera de las tareas intelectuales que se le presuponen a un ser humano con una inteligencia normal.
} 
que ocurriría si un ordenador exhibiera un comportamiento indistinguible al de los seres humanos, dado que el filósofo encerrado en la habitación se habría comportado exactamente como un ordenador: habría realizado operaciones computacionales sobre elementos especificados sólo formalmente. Y no habría entendido nada, a pesar de aparentemente haber mostrado inteligencia ${ }^{18}$.

En su propio artículo pretende dar respuesta a varias críticas o réplicas a su argumento y en la que denomina "réplica de los sistemas» Searle (1980, p. 419) expone que, a pesar de que efectivamente la persona encerrada en la habitación no habría entendido, en realidad esa persona es sólo una parte de un sistema que se compone de más elementos: la lista de símbolos o programa, papel y lápiz para realizar los cálculos, y las «bases de datos» de las posibles preguntas y respuestas. Así, la comprensión no podría predicarse de una sola de las partes del sistema, sino del sistema en su conjunto del que la persona en ese ejemplo es parte. Searle responde a esta replica suponiendo que la persona encerrada memorizara las reglas y el resto de los elementos del sistema llevando a cabo todos los cálculos en su cabeza: aun así, seguiría sin entender nada.

Sin embargo, Searle parece no entender las implicaciones de su réplica. En primer lugar, es un error decir que el filósofo encerrado en la habitación no ha entendido nada. A pesar de que no pueda entender la comunicación que se imita mediante el intercambio de mensajes, sí entiende perfectamente lo que está haciendo: asigna a preguntas que le son dadas respuestas predeterminadas en una lista identificándolas por la forma de cada signo. Su entendimiento es incompleto, pero si consideramos al filósofo encerrado en la habitación como un sistema, ese sistema sí puede describir perfectamente lo que hace si describe la regla que sigue. Igualmente, el sistema que constituye la lista de preguntas y respuestas también "entiende» algo, aunque sea de manera incompleta. Entiende que a la cadena de signos chinos «hola, ¿cómo te llamas?» corresponde, por ejemplo, la respuesta «soy Searle, el filósofo», así como entiende el resto de correspondencias. Este sistema puede ser ininteligible para Searle, pero eso no significa que no tenga sentido. Y seguirá siendo ininteligible aunque lo memorice, ya que en realidad, aunque parezca haberlo integrado, el sistema-filósofo no ha interiorizado las reglas del sistemaprograma que se encuentran en relación directa y obedecen al lenguaje chino. Esto es a lo que se refiere la «réplica de los sistemas» cuando afirma que sólo si se integran todos los sistemas que toman parte en la acción se entiende plenamente el sentido de lo que el filósofo encerrado en la habitación está haciendo.

En términos muy parecidos expone Rapaport (1988) su argumento de la habitación coreana como respuesta a Searle. Imaginemos un profesor coreano de literatura inglesa que, pese a no entender inglés, fuese una autoridad en Shakespeare. Sólo ha leído a Shakespeare a través de excelentes traducciones al coreano, y basándose en sus lecturas y en sus propias capacidades ha escrito en coreano numerosos artículos sobre la obra del dramaturgo inglés que han sido traducidos al inglés para prestigiosas revistas académicas. Rapaport se pregunta si el profesor coreano "entiende» a Shakespeare y responde que sí. No lo entiende directamente, por supuesto, sino por mediación de un sistema que lo traduce, así que en realidad la comprensión sólo se produce mediante la integración de los sistemas involucrados. Esto es lo que Narayanan (1997) denomina réplica de sistemas -systems reply- de manera que la inteligencia surge de procesos computacionales y

\footnotetext{
${ }^{18}$ Es decir, supera el Test de Turing al demostrar capacidad para exhibir comportamientos, conductas o respuestas inteligentes que son equivalentes, o al menos indistinguibles, de las humanas. Aunque existe controversia al respecto, desde que fuera diseñado por Turing (1950) ninguna máquina/programa ha superado hasta ahora el test y sus sucesivas reformulaciones.
} 
de las interacciones entre esos procesos. Si esos procesos son mentales, físicos o conductuales, es irrelevante. El sistema en su conjunto se mueve a través de varios estados denominados estados representacionales, de manera que el siguiente estado es determinado por el anterior como suma de todas las entradas -inputs- o integraciones.

Para Rapaport la comprensión «semántica» es una cuestión de correspondencia entre dominios: un agente cognitivo entiende un dominio en referencia a otro, que a su vez referiría a otro sucesivamente hasta llegar a un dominio -puramente sintáctico o formal- que pudiese entenderse exclusivamente en referencia a sí mismo ${ }^{19}$. Esto le lleva a afirmar la posibilidad de una sintáctica con valor semántico, algo que nos parece un error en términos absolutos, dado que aquí Rapaport estaría desconociendo que cuando decimos que algo es formal o material lo hacemos necesariamente con un carácter situacional. Es decir, no podemos predicarlo absolutamente, sino siempre con respecto a algo ${ }^{20}$. Y así, por ejemplo, el tipo penal será material respecto al derecho procesal que lo aplica, y será formal respecto a los hechos que se aplican o, más técnicamente, subsumen a ese tipo ${ }^{21}$. Es decir, tal y como afirman los teóricos de la Inteligencia Artificial, los procedimientos sí tienen un componente o valor semántico, pero este valor no puede predicarse absolutamente sino situacionalmente, es decir, siempre ya sea en relación a otros procesos-funciones o en relación a sí mismos en un momento lógicamente anterior.

\section{Aproximación desde la Teoría política}

Las teorías con base procedimental-formal denominadas habitualmente procesualistas o formalistas, ya en el ámbito del Derecho o en el de la Teoría Política, se caracterizan por su pretensión de fundamentación de los sistemas a los que hacen referencia mediante reglas que, dada su naturaleza estrictamente formal-procesal, no comportarían en cuanto tales una toma de posición axiológica. En este sentido, estas teorías se orientarían a establecer, desde ese suelo común, criterios de legitimidad procedimental irrefutables en nuestras democracias actuales, socialmente

\footnotetext{
19 "What does it mean to understand language? "Semantic" understanding is a correspondence between two domains; a cognitive agent understands one of those domains in terms of the other. But if one domain is to be understood in terms of another, how is the other understood? Recursively, in terms of yet another. But, since recursion needs a base case, there must be a domain that is not understood in terms of another. So, it must be understood in terms of itself. How? Syntactically! Put briefly, bluntly, and a bit paradoxically, semantic understanding is syntactic understanding». (Rapaport, 1995, p. 49).

20 Desde un máximo nivel de abstracción, donde la interpretación no derive de la correspondencia o llamada a otros dominios, surge la idea de recursividad. Un objeto es recursivo si en parte se encuentra formado por sí mismo, de manera que la recursividad consiste en la propiedad que tienen procedimientos y funciones de llamarse a sí mismos para resolver un problema. Pero, incluso en ese caso la definición formal del objeto opera como procedimiento para la primera y sucesivas llamadas. «El método recursivo de definición de funciones está íntimamente conectado con el método de inducción matemática, un proceso que puede verse implícitamente en el trabajo de Euclides». (Adams, 2011, p. 2).

21 Identificar el derecho procesal como derecho adjetivo es incorrecto, pues la relación situacional adjetivo-sustantivo no sólo se da entre derecho procesal y sustantivo, sino entre las propias normas procesales. Así, «hay normas procesales que miran a la sustancia misma de la situación que regulan, como la que da derecho a terceros que se creen lesionados, para concurrir a un juicio; la que otorga el derecho de pedir la ejecución del deudor con base en un título ejecutivo; la que consagra el derecho de apelación o el recurso de casación. $Y$ hay otras normas que miran a la forma de los actos, a la manera como esa intervención de terceros, o esa demanda ejecutiva, o esos recursos, deben formularse o ejercitarse; estas son normas formales propiamente dichas». (Devis Echandía, 1966, p. 42). «En conjunto, la idea de que el derecho procesal es, por su función y en relación al derecho material, un quid secundario, mediato o instrumental, se halla tan arraigada, que en las doctrinas más dispares la vemos aparecer con denominaciones y fórmulas más o menos afortunadas; esta idea, en efecto, es la que ha llevado a construir las conocidas dualidades de derecho sustantivo y derecho adjetivo, de derecho material y derecho instrumental, o, todavía peor, derecho formal, de derecho determinador y derecho sancionador». (Guasp, 1943, p. 38).
} 
caracterizadas por el multiculturalismo, la complejidad y la falta de consenso respecto a incuestionables valores básicos sustantivos. Solo los procedimientos, en virtud de ese supuesto estatuto de neutralidad e imparcialidad, serían susceptibles de garantizar el consenso que conformaría ese sólido cimiento al que aspira toda democracia.

Mientras que las interpretaciones metafísico-religiosas del mundo nos proveían de una cómoda certeza en relación a lo que podíamos saber y a lo que debíamos hacer, la situación se trastoca radicalmente en la modernidad. Tal y como señala Habermas $(1999$, p. 37) «con el paso al pluralismo cosmovisivo en las sociedades modernas, la validez de las normas morales universalmente vinculantes ya no se puede explicar en ningún caso con razones e interpretaciones que presuponen la existencia y el papel de un Dios creador y redentor trascendente», lo que comportará además un desplazamiento de la autoridad epistémica, que pasa de las doctrinas religiosas a las modernas ciencias experimentales. A raíz de la modernidad, el ethos común se encuentra en ruinas, de forma que para Habermas la filosofía moral se enfrenta a la obligación de tejer una nueva fundamentación postmetafísica de nuestras sociedades democráticas.

En este sentido, los teóricos de la llamada democracia deliberativa, en sus dos vertientes rawlsiana y habermasiana, llevan más de cuarenta años intentando desarrollar modelos de democracia procedimental basados en modelos formales que en sus fundamentos deriven su normatividad estrictamente de su carácter racional. Si esto fuera efectivamente posible, estos modelos comportarían una gran ventaja dado que el consenso respecto a los procedimientos que sustenta la democracia liberal tendría carácter necesario, so pena de irracionalidad. Es decir, no estaríamos hablando de un mero acuerdo estratégico, sino de un verdadero consenso racional motivado por razones epistémicas capaces de establecer una definición intersubjetiva del bien. $Y$ en este sentido, la teoría habermasiana entiende que este consenso es susceptible de lograrse mediante la implementación de procesos imparciales que favorezcan el debate público racional y la apertura de sus participantes, a fin de que sean receptivos al mejor argumento. En este sentido, la propuesta habermasiana de la «comprensión paradigmática de fondo» del derecho y de la Constitución pretende exponer el carácter racional de la autocomprensión práctico-moral de la modernidad en su conjunto, y por lo tanto, su valor epistémico-normativo. Para ello, dice Habermas (1998, p. 59) «la teoría del discurso es una tentativa de reconstruir esta autocomprensión, de modo que pueda afirmar su propia especificidad normativa, tanto frente a las reducciones cientifistas, como frente a las asimilaciones estéticas». Desde el planteamiento procesualista se pretende, en definitiva, reconstruir -en un sentido kantiano- una fundamentación del ejercicio del poder político susceptible de reemplazar en sus funciones tradicionales a la legitimación metafísico-religiosa, de manera que el cumplimiento del orden jurídico legítimo obedezca a razones morales deducidas mediante procedimientos racionales.

Ahora bien, para Habermas es esencial que estos procedimientos no presupongan las razones morales que se pretenden deducir, dado que en ese caso se estaría incurriendo en una petición de principio. $Y$ es a esto a lo que se refiere cuando señala que la justicia como equidad de Rawls es sustantiva en vez de procedimental, pues su constructivismo político «le arrastra nolens volens hacia la disputa entorno a los conceptos de racionalidad y verdad» (Habermas, 1998a, p. 71).

En relación al asunto que nos ocupa, resulta muy interesante la réplica de Rawls a Habermas respecto a esta cuestión, pues al señalar la relación entre la justicia procedimental y la justicia sustantiva, Rawls deja entrever cuáles son, a nuestro juicio, los verdaderos límites, y hasta dónde puede aspirar cualquier 
fundamentación procedimental del poder y el derecho. En este sentido, tanto la justicia procedimental (referida a la justicia o equidad de un procedimiento) como la justicia sustantiva (referida a su resultado) comportan para Rawls valores que «van juntos en el sentido de que la justicia de un procedimiento siempre depende (dejando a un lado el caso especial del juego) de la justicia de su resultado probable, o de la justicia sustantiva. Así, la justicia procedimental y la sustantiva están conectadas y no van separadas» (Rawls, 1998), de manera que no puede existir acuerdo sobre la primera que no presuponga un consenso entrecruzado en relación a la segunda. Y precisamente por esto, Rawls entiende que la concepción de Habermas también es sustantiva en el fondo, aun cuando los elementos sustantivos de ambas teorías puedan diferir.

Esto se traduce, a juicio de Chantal Mouffe, en la imposibilidad de ambas teorías procesualistas para llevar a cabo lo que anuncian, de manera que «la teoría democrática debería renunciar a estas formas de escapismo y enfrentarse al reto que conlleva el reconocimiento del pluralismo de valores. Esto no significa aceptar un pluralismo total, [sino] reconocer la naturaleza política de los límites en lugar de presentarlos como un conjunto de requisitos exigidos por la moral o la racionalidad» (Mouffe, 2012, p. 107). El verdadero problema no sería encontrar argumentos que sean aceptables para toda persona racional o razonable, pues los principios liberaldemocráticos sólo pueden defenderse como elementos constitutivos de nuestra forma de vida. Siguiendo a Wittgenstein, Mouffe señala que los procedimientos se pueden seguir y pueden ser aceptados debido a que se hallan inscritos en formas compartidas de vida y en acuerdos sobre juicios. O dicho de otro modo: las reglas son siempre formas abreviadas de las prácticas, inseparables de las formas específicas de vida.

De esta manera, «la distinción entre lo que es de carácter procedimental y lo que es de carácter sustancial no puede estar tan clara como la mayoría de los teóricos liberales querrían» (Mouffe, 2012, pp. 82-83). En el caso de la justicia, señala Mouffe, esto implica que no es posible oponer justicia procedimental y sustancial sin reconocer que la justicia procedimental implica ya la aceptación de ciertos valores, pues el diseño de cualquier procedimiento presupone necesariamente compromisos éticos sustanciales. Y esto tiene consecuencias muy importantes, pues no será posible defender los valores que sustentan la democracia liberal en virtud de un consenso racional que no implique un compromiso axiológico. Sino justamente al contrario: debemos asumir que el ethos democrático no tiene carácter neutro ni necesario, sino que procede de una concreta decisión histórica y que sus valores son contingentes en cuanto se vinculan a determinadas formas de vida.

\section{Conclusión}

Las construcciones de carácter procedimental-formal pretenden evitar el problema de la fundamentación axiológica del poder y el derecho en sociedades multiculturales complejas que no pueden describirse a sí mismas mediante un solo relato de carácter metafísico-religioso unificador, dado que en el seno de dichas sociedades conviven simultáneamente gran variedad de relatos omnicomprensivos, y por lo tanto, contradictorios. Resulta tranquilizador pretender que las garantías procesales carecen de carácter sustantivo, y que por lo tanto pueden fundar el consenso al margen de conflictos de valores y disputas políticas. Pretender que el procedimiento debido no es sustantivo porque es procedimental, y que por lo tanto la jurisprudencia constitucional se sitúa al margen de estos conflictos cuando decide sobre procedimientos. Sin embargo, la realidad es que los procedimientos funcionan justamente al contrario, de manera que si son efectivamente útiles en las sociedades democráticas es porque precisamente incorporan acuerdos axiológicos previos. 
Los procedimientos contienen elementos adjetivos y sustantivos en función de la situación en la que consideramos esos elementos, es decir, en relación a si determinan o son determinados en la cadena de eventos que constituye la acción definida por el proceso. Constituye un error presentar al proceso como algo ajeno o en situación de aislamiento respecto a cualesquiera elementos sustantivos pues la relación formal-material en el sentido lógico-semántico a que hace referencia la norma jurídica debe interpretarse pragmáticamente -es decir, en su aplicación a casos prácticos- de acuerdo a los mismos principios definidos por Aristóteles con carácter general para la relación forma-materia. Y así, la afirmación aristotélica que señala que «la materia es algo relativo, pues para una forma se requiere una materia y para otra forma otra materia» (Aristóteles, 1995, p. 139), refiere el carácter situacional con el que debemos interpretar la relación forma-materia en cuanto obedece a esos mismos principios lógicos. Un ente determinado puede ser, según el caso, forma y materia al mismo tiempo (los ladrillos, por ejemplo, son al mismo tiempo la materia de la casa y la forma del barro cocido del que se componen) y así, el «concepto de materia no es absoluto, sino relativo: no indica una cosa o realidad determinada, sino un punto de vista desde el que mirar cualquier cosa o realidad, punto de vista correlativo al de forma o estructura. Todo compuesto es materia estructurada, pero lo que es materia respecto a esa estructura es forma respecto a su propia materia. [...] materia y forma no se refieren a realidades absolutas, sino a puntos de vista que en cada caso enfocan algo distinto» (Mosterín, 2000, pp. 125-127).

Del mismo modo, sobre el par formal/material se construyen campos semánticos intercambiables precisamente porque obedecen a nuestra situación al describir la realidad y a la voluntad denotativa del proferente. Así, decimos que lo retórico tiene un carácter formal, y eso significa ampuloso, ceremonioso, vacuo y superficial, mientras que lo lógico tiene también un carácter formal pero con un significado de algo muy preciso y con contenido. Ambos términos son formales, pero a distinto nivel, es decir, nunca uno respecto al otro. El salto lógico consiste en modificar inadvertidamente ese nivel de referencia, pues siempre uno será (más) formal con respecto al otro, que será (más) sustantivo. Desde el punto de vista del razonamiento práctico se incurre en este error al categorizar dicha oposición como estrictamente binaria, desconociendo el resto de niveles de referencia. Es decir, algo puede tener carácter procedimental-formal (en referencia a algo más sustantivo) y al mismo tiempo poder entenderse como sustantivo-material (en referencia a algo más procedimental).

De esta manera, lo sustantivo no es algo diverso y contradictoriamente opuesto a lo formal, sino que es lo formal nuevamente, pues «la materia de algo, en cuanto tal materia, es siempre incognoscible. Solo es cognoscible en cuanto provista de forma, pues la forma es lo único que podemos conocer» (Mosterín, 2000, p. 127). Lo sustantivo es otra vez lo formal, aunque esta vez expresado desde un nivel superior, asignándole o pretendiendo deducir de él un significado de contenido más tangible y concreto, más contextualizado, y por eso, de alguna manera "más real". Esta última idea es de la mayor importancia, pues evidencia lo característico del par formal-material, que no es directamente equiparable ni subsumible en lo abstractoconcreto. Lo sustantivo no es simplemente lo concreto, sino lo concreto en un nivel pragmático, de manera que lo sustantivo no puede darse mediante un ajuste automático de los límites adjetivos, sino que precisa referirse a un contexto. Y así, por ejemplo, la formalización lógico-matemática de un escrito en lenguaje ordinario representa su contenido formal al señalar su estructura adjetiva, mientras que ese discurso escrito, al constituir la traducción en lenguaje común de su fórmula lógica, es sustantivo con respecto a ésta pero será adjetivo respecto a su contextualización retórica, pues la prosodia, el contexto entendido como entramado referencial, y la 
oportunidad de su expresión en un momento y lugar concreto, implicarán una nueva concreción sustantiva ceñida a los límites a priori del texto escrito.

La tentación formalista consiste en creer que es posible la toma de decisiones que involucren juicios de valor mediante procedimientos abstractos que no presupongan elementos valorativos previos, de manera que el consenso sobre un supuesto carácter de neutralidad axiológica de los procedimientos impregne de legitimidad tales decisiones en cuanto sus resultados. Sin embargo, nos parece que de lo expuesto hasta ahora se deduce que no es posible obtener coherentemente -es decir, sin incurrir en una contradicción performativa- un resultado justo sin que medie un procedimiento que se ajuste en sí mismo a los parámetros sustantivos básicos que definen ese resultado justo. No existen procesos de toma de decisiones axiológicamente neutros que den como resultado juicios de valor. $Y$ los que se presentan como tales, sólo remiten a dos posiciones: [a] o bien se configuran desde un consenso de valores previo que difumina el hecho de que esos valores no son los únicos racionalmente posibles, de manera que sí han sido efectivamente elegidos entre otras alternativas -que desde esa situación de consenso parecen contextualmente inconcebibles-, o [b] se pretenden fundados en ese consenso que hemos definido en [a] con el propósito de ocultar otras alternativas posibles que sí son concebibles en esas circunstancias.

\section{Bibliografía}

Adams, R. (2011). An Early History of Recursive Functions and Computability. From Gödel to Turing. Boston, USA: Docent Press.

Aristóteles (1995). Física. Madrid, España: Gredos.

Borges, J.L. (1971). Tlön, Uqbar, Orbius Tertius. En compilación del mismo autor: Ficciones. El jardín de Senderos que se Bifurcan (pp. 13-36). Barcelona, España: Alianza.

Coke, E. (1642). Institutes of The Laws of England, Part II. London, UK.

Dawkins, R. (1976). The Selfish Gene. Oxford, UK: Oxford University Press.

Devis Echandía, H. (1966). Nociones Generales de Derecho Procesal. Madrid, España: Aguilar.

Easterbrook, F.H. (1982). Substance and Due Process. The Supreme Court Review, Vol. 1982, 85-125.

Ely, J.H. (1980). Democracy and Distrust. Cambridge, USA: Harvard University Press.

Guasp, J. (1943). Comentarios a la Ley de Enjuiciamiento Civil. Madrid, España: Aguilar.

Greene, J. (2016). The Meming of Substantive Due Process. Constitutional Commentary, 21, 253-294.

Habermas, J. (1998a). Facticidad y Validez. Madrid, Espña: Editorial Trotta. Traducción de Manuel Jiménez Redondo.

Habermas, J. (1998b). Reconciliación y Uso Público de la Razón. En F. Vallespín (Ed.), Debate Sobre el Liberalismo Político (pp. 41-74). Barcelona, España: Paidós. Traducción de Gerard Vilar Roca.

Habermas, J. (1999). La Inclusión del Otro. Barcelona, España: Paidós. Traducción de Gerard Vilar Roca.

Keynes, E. (1996). Liberty, Property, and Privacy. Toward a Jurisprudence of Substantive Due Process. University Park, USA: Pennsylvania State University Press.

Kannar, G. (1990). The Constitutional Catechism of Antonin Scalia. Yale Law Journal, Vol. 99 (No. 6), 1297-1357.

Mosterín, J. (2000). Conceptos y Teorías en la Ciencia. Madrid, España: Alianza. 
Mouffe, C. (2012). La Paradoja Democrática. El Peligro del Consenso en la Política Contemporánea. Barcelona, España: Gedisa.

Narayanan, A. (1997). Biomolecular Cognitive Science. En Nualláin et al. (Ed.), Two Sciences of Mind (pp. 21-37). Amsterdam, Países Bajos: John Benjamin Publishing.

Newell, A. y Simon, H.A. (1976). Computer Science as Empirical Enquiry: Symbols and Search. Communications of the ACM, 3 Vol. 19 (March), 113-126.

Rapaport, W.J. (1988). Syntactic Semantics: Foundations of Computational NaturalLanguage Understanding. En James H. Fetzer (Ed.), Aspects of Artificial Intelligence (pp. 81-131). Dordrecht, Países Bajos: Kluwer Academic Publishers.

Rapaport, W.J. (1995). Understanding Understanding: Syntactic Semantics and Computational Cognition. Philosophical Perspectives, Vol. 9, 49-88.

Rawls, J. (1998). Réplica a Habermas. En F. Vallespín (Ed.), Debate Sobre el Liberalismo Político (pp. 75-146). Barcelona, España: Paidós. Traducción de Gerard Vilar Roca.

Scalia, A. (1997). Common-Law Courts in a Civil-Law System. En A. Gutmann (Ed.), A Matter of Interpretation: Federal Courts and The Law (pp. 3-49). Princeton, USA: Princeton University Press.

Searle, J. (1980). Minds, Brains, and Programs. Behavioral and Brain Sciences, 3, 417-457.

Turing, A.M. (1950). Computing Machinery and Intelligence. Mind, New Series, Vol. 59, No. 236 (October), 433-460.

Tribe, L.H. (2000). Substantive Due Process. En L.W. Levy y K.L. Karst (Ed.), Encyclopedia of the American Constitution (pp. 2569-2575). New York, USA: Macmillan.

Tribe, L.H. (1980). The Puzzling Persistence of Process-Based Constitutional Theories. Yale Law Journal, Vol. 89, No. 6, 1063-1080.

Tribe, L.H. (1997). Comment. En A. Gutmann (Ed.), A Matter of Interpretation: Federal Courts and The Law (pp. 65-94). Princeton, USA: Princeton University Press. 